\title{
Improving hydraulic fracturing effectiveness in depleted and low-pressure reservoirs using $\mathrm{N}_{2}$-energized fluids
}

\author{
A. A. Elgibaly ${ }^{1}$ A. M. Salem ${ }^{1} \cdot$ Y. A. Soliman ${ }^{2}$
}

Received: 19 August 2020 / Accepted: 26 November 2020 / Published online: 6 January 2021

(c) The Author(s) 2021

\begin{abstract}
Foamed and energized fluids fracturing has been used in both conventional and unconventional reservoirs, as they reduce the amount of water used and hence minimize deleterious impact on water-sensitive formations. They also aid in the flow back after treatment in reservoirs where drawdown is limited. In this paper, the most important foam properties are presented, in addition, when to use energized fluids fracturing and how to choose the best energizing component with the best quality. The impact of $\mathrm{N}_{2}$-energized fluids fracturing (NEF) on wells that were previously fractured using conventional fracturing fluids is also presented. In addition, a comparison between the results of $\mathrm{N}_{2}$-energized fluids fractured and conventional fluid fractured wells is presented. The effect of using 20 to $50 \%$ (NEF) on production through surface well testing and live production data showed excellent and sustainable production rates. An economical study is presented through comparing the total capital cost of both NEF and conventional fluids fracturing, in addition to the hydrocarbon recovery of wells after both types. Data considered in this work represent about 40 wells fractured using NEF in the Egyptian Western Desert.
\end{abstract}

Keywords Foam quality $\cdot$ Energizing component $\cdot$ Nitrogen-energized fluids $\cdot$ Conventional fracturing fluids $\cdot$ Lowpressure reservoirs

$\begin{array}{ll}\text { Abbreviations } & \\ \text { NEF } & \text { Nitrogen-energized fluids } \\ \text { BHP } & \text { Bottom-hole pressure, psi. } \\ \text { BHT } & \text { Bottom-hole temperature, f. } \\ \text { K } & \text { Reservoir permeability, md. } \\ \mathrm{E} & \text { Young's modulus, psi. } \\ \nu & \text { Poison's ratio } \\ X_{f} & \text { Fracture half-length, } \mathrm{m} \\ H_{f} & \text { Fracture height, } \mathrm{m} \\ W_{f} & \text { Fracture width, in } \\ \text { FC } & \text { Fracture conductivity, md.ft } \\ \text { W.C. }_{{ }_{\mathrm{o}}} & \text { Pre-fracturing water cut, } \% \\ \mathrm{Q}_{\mathrm{o}} & \text { Pre-fracturing gross rate, bpd } \\ \text { W.C. }_{\mathrm{f}} & \text { Post-fracturing water cut, } \% \\ \text { FOI } & \text { Fold of increase, unitless and given by } \\ & Q_{f} / Q_{\mathrm{o}} \\ \mathrm{Q}_{\mathrm{f}} & \text { Post-fracturing gross rate, bpd } \\ \end{array}$

Y. A. Soliman

yehyaali07@gmail.com

1 Faculty of Petroleum and Mining Engineering, Suez University, Suez, Egypt

2 Faculty of Petroleum and Mining Engineering, Badr El-Din Petroleum Company, Suez University, Suez, Egypt

$\begin{array}{ll}\text { ARG } & \text { Abu Roash G Formation } \\ \text { ARE } & \text { Abu Roash E Formation } \\ \text { BAH } & \text { Bahariya Formation } \\ \text { U.BAH/ M.BAH } & \text { Upper and middle Bahariya Formation } \\ \text { N } & \text { Original oil in place } \\ \text { A5 } & \text { Appolonia 5 Formation } \\ \text { A.BUEIB } & \text { Allam Al-BUEIB Formation } \\ \text { L.SAFA } & \text { Lower SAFA formation } \\ \text { EUR } & \text { Estimated ultimate recovery }\end{array}$

\section{Introduction}

Foam stimulation became one of the major techniques used for fracturing oil and gas wells. Foam is a dispersion of gas phase inside liquid phase, where $\mathrm{CO}_{2}$ or $\mathrm{N}_{2}$ gas is the internal phase, and liquid such as water, oil or even alcohol is the external phase (Gandossi. 2013). During foam production, a compatible surfactant must be used to combine both phases to maintain foam stability during the treatment as illustrated in (Montgomery. (2013)). Generally, most of the foam properties including its rheology and viscosity are controlled by the foam quality, which is the percent of gas phase volume 
to the total volume of fluid used (gas + liquid). The foam quality is given by:

Foam quality $=\frac{V_{\text {gas }}}{V_{\text {gas }}+V_{\text {liquid }}} \%$

As illustrated in (Mitchell. (1969)) \& (David and Marsden 1969), $\mathrm{N}_{2}$ is the oldest foaming gas, and its use dates to 1960 as indicated in (Petty et al. 1964). The other gas commonly used is $\mathrm{CO}_{2}$ and its use started in the early 1980s as represented in (Bullen and Lillies 1983). Due to flow-back challenges in low-pressure formations, foam-based fluids become very common for use in low-pressure reservoirs. Recently, the US Department of Energy (DOE) is focusing to identify a thermodynamic pathway to utilize natural gas (NG) obtained from producing wells in foam fracturing (Beck and Verma 2016) \& (Verma 2016). Later, the study was extended into laboratory-scale experiments to measure NG-foam fluid rheology, and it was found to be similar to foams based on $\mathrm{N}_{2}$ and $\mathrm{CO}_{2}$ (Beck, et al. 2017). The use of NG as an energizer has not been practiced widely yet, but applications of NG foamed field test and reaping the economic benefit from simplified logistics and improved production would enable operators to invest in improving the use of NG foams for wellsite treatments.

Typical foams exist when the foam quality ranges between 52 and $95 \%$, and at foam qualities greater than $95 \%$, the gas becomes the external phase and referred to as mist flow as illustrated in (Economides and Nolte 2000). Stable dispersions of gas in liquids can also be prepared with qualities less than 52\% which can be called foams or energized fluid as in (Watkins et al. 1983).

A hydraulic fracturing treatment can be energized by introducing a compressible gaseous component into the treating fluid. The gaseous component inside the energized fluid treatment expands when the treatment is completed and pressure is released. This facilitates the flow back of treatment fluids post-treatment. Energizing the fracturing fluid can be used for many reasons, but mainly its applications are in reservoirs that have a low pore pressure, low permeability or water-sensitive formations.

Stimulation of depleted and low-pressure reservoirs became one of the most important challenges in the past decade. When using conventional fluids in fracturing these reservoirs, the results were very disappointing, due to the formation damage caused by these fluids and the disability of reservoir pressure to overcome the fluid column in the well, as well as flow-back fracturing fluids after treatment.

Recently, energized fluid fracturing showed very good and satisfactory results in depleted and low-pressure reservoirs. In addition, it showed excellent production results when used in high-pressure reservoirs. The use of $\mathrm{CO}_{2}$ or $\mathrm{N}_{2}$ in energizing fluids in foam fracturing can reduce the amount of water up to $90 \%$ (depending on the foam quality). This consequently reduces the damage caused by water in low-pressure reservoirs. They are becoming very popular for use in stimulation treatments of depleted and low-pressure reservoirs. This is due to their excellent properties such as low leak-off rates, excellent proppant transfer capacity, longer fractures with less fluids, minimum formation damage and superior energetic post-treatment cleanout.

\section{Energized fluids properties}

\section{Composition and rheology}

The most popular foams are made from nitrogen, water and a foaming surfactant. At first, the surfactant is mixed with the liquid phase, and then, the injection of both gas and surfactant solution into the well (Haugen 2014) explains this operation in detail. Simple water foams have low viscosity relative to gelled water foams and a shorter half-life. They are used in shallow wells with low bottom-hole temperatures, and where only low proppant concentrations are required. They are also used in wells where damage due to gelling agent is critical. Adding a gelling agent extends the half-life of the foam for treatments of linear gel (non-crosslinked) which gives increased viscosity to foams over that of water-only foams. The additional viscosity produces greater fracture width to allow higher proppant concentrations to be placed. The use of delayed cross-linking agents in foam fluids greatly multiplies the viscosity obtained by foam fluids. The higher viscosity fluid creates greater fracture width for easier proppant placement and lower fluid leak-off. Sand concentrations as high as $12 \mathrm{lb} / \mathrm{gal}$ have been successfully placed. The cross-linked gel liquid phase imparts much longer half-life to the foam and leaves a cross-linked gel filter cake. So, it is important to break the gel prior to flow back. Failure to break the gel will limit the fluid recovery.

Figure 1 illustrates viscosity generated in water foamed with $\mathrm{N}_{2}$. Little viscosity increase is noted until the gas quality gets above $52 \%$. Above $52 \%$ quality, the viscosity increase is exponential. Viscosity also decreases with shear rate, showing that foam is a shear-thinning-type fluid, i.e., foam viscosity is low in high-shear conditions such as pumping down tubing and higher in low-flow, laminar condition such as flowing down a fracture system carrying proppant. Cross-linking the liquid phase will compensate for the decrease in viscosity caused by using low foam qualities that are less than $52 \%$. This makes it possible to use foam qualities less than $52 \%$ with higher viscosity and good proppant carrying capacity. 


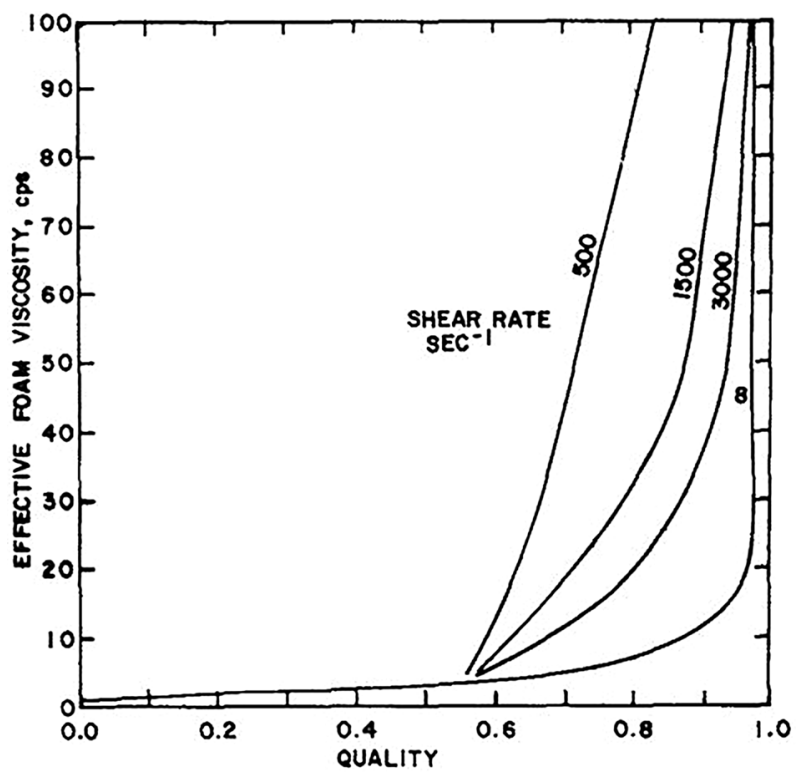

Fig. 1 Effect of foam quality on foam viscosity (Steven et al. 1983)

\section{Proppant carrying capacity}

In foam fracturing, the viscosity of the created foam is much more than each of the single phases comprising the foam. This gives foam a higher viscosity than other conventional fracturing fluids such as water. This assists in even mixing of the fracturing fluid during the treatment and reducing proppant sedimentation. Slick-water fracturing creates longer fractures compared to $\mathrm{N}_{2}$-energized treatments, but leaves much of the fracture length created un-propped compared to the $\mathrm{N}_{2}$-energized treatments; therefore, foams and energized fluids are more suitable than slick-water in carrying proppant throughout the fractures. According to (McAndrew 2014), the proppant distribution inside the created fracture is of great importance as it affects the reservoir performance. Foam and energized fluids create the optimum desired proppant distribution inside the fracture with high proppant concentration, compared to other conventional fracturing fluids as illustrated in (Yu 2015).

\section{Energized fluids selection and quality control}

\section{Applications of energized fluids over conventional fluids}

The use of energized fracturing fluids is determined based on the drawdown level in the formation, which is classified high or low based on the capillary pressure, which in turn is a function of formation permeability. For drawdown pressure lower than the capillary pressure limit, energized fracturing is highly recommended. In the case that the drawdown pressure is high (more than the capillary pressure limit), it makes no difference to use energized fracturing over conventional fracturing, where the conventional fracturing fluids would give the same results. As the drawdown is sufficient to recover the fracturing fluids after treatment, the use of energized fracturing can be justified to tight and low-pressure formations.

\section{Choosing the best energizing component}

After determining that energizing the fluid is the way to go, it is necessary to evaluate which energizing component works best. In this section, we evaluate the most popular energizing components: $\mathrm{N}_{2}, \mathrm{CO}_{2}$ and binary systems of both $\mathrm{N}_{2}$ and $\mathrm{CO}_{2}$ as illustrated in Table 1. It is obvious that $\mathrm{N}_{2}$ is more familiar, available and easier to handle than $\mathrm{CO}_{2}$. However, $\mathrm{CO}_{2}$ is preferred to use over $\mathrm{N}_{2}$ if the adequate environment and equipment are available due to:

- Higher solubility in water.

- Compatibility with formation fluids.

- Lower surface treating pressures.

- Accessibility to deeper reservoirs.

- In addition, it is considered an EOR method as it dissolves in oil and decreases its viscosity.

\section{Choosing the optimum foam quality}

After deciding that energized fluid fracturing is the way to go and determining which energizing component works best, now it is time to determine the optimum foam quality to be used. Studies showed that longer but thinner fractures result from lower quality (20-30\%) and shorter but more conductive fractures result from high quality (60-70\%). For most tight reservoirs, it is required to have a longer and thinner fracture to increase the contact area with the reservoir; this is why the lower quality fluids are preferred.

To conclude, 30 to $50 \%$ quality energized fluids are recommended because they allow enough gas to saturate the liquid while giving the best fracture dimensions for tight reservoirs. Higher quality (up to 70\%) may be necessary if shorter and wider fractures are required.

\section{Objectives of this study}

The objectives of this study are to demonstrate that:

1. 20 to $50 \%$ quality energized fluids are optimum for use in the Egyptian Western Desert. 


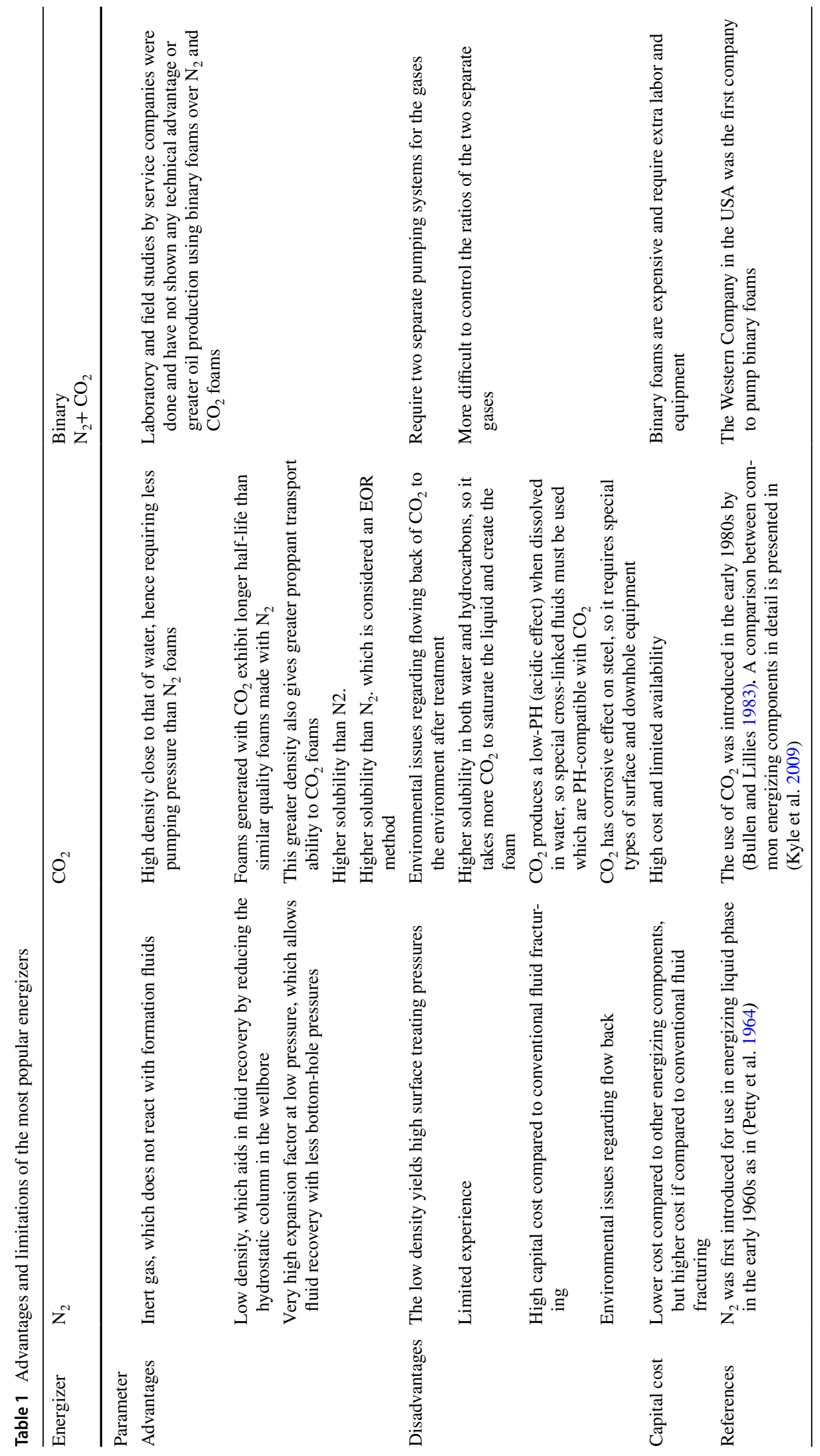




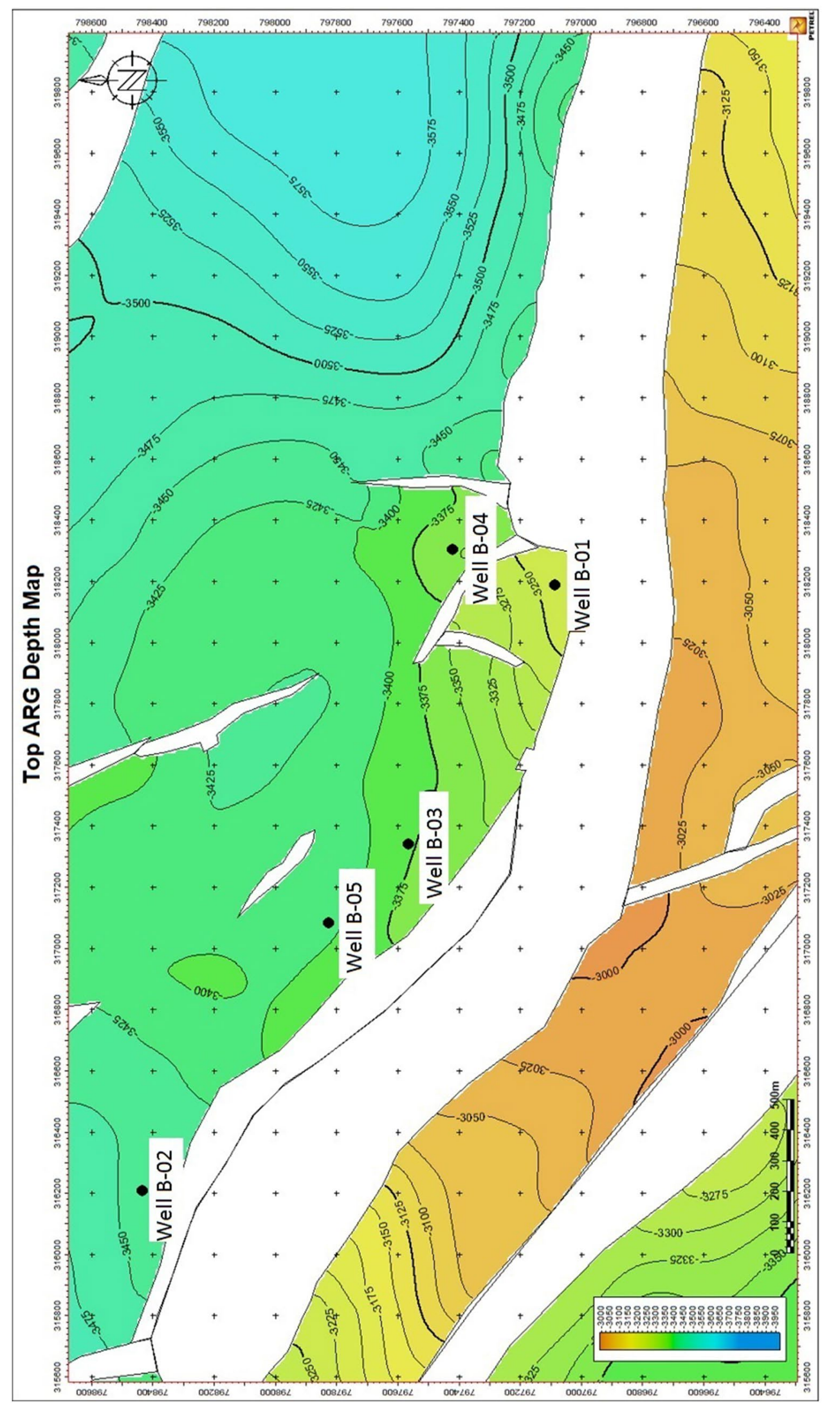

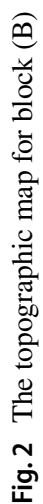




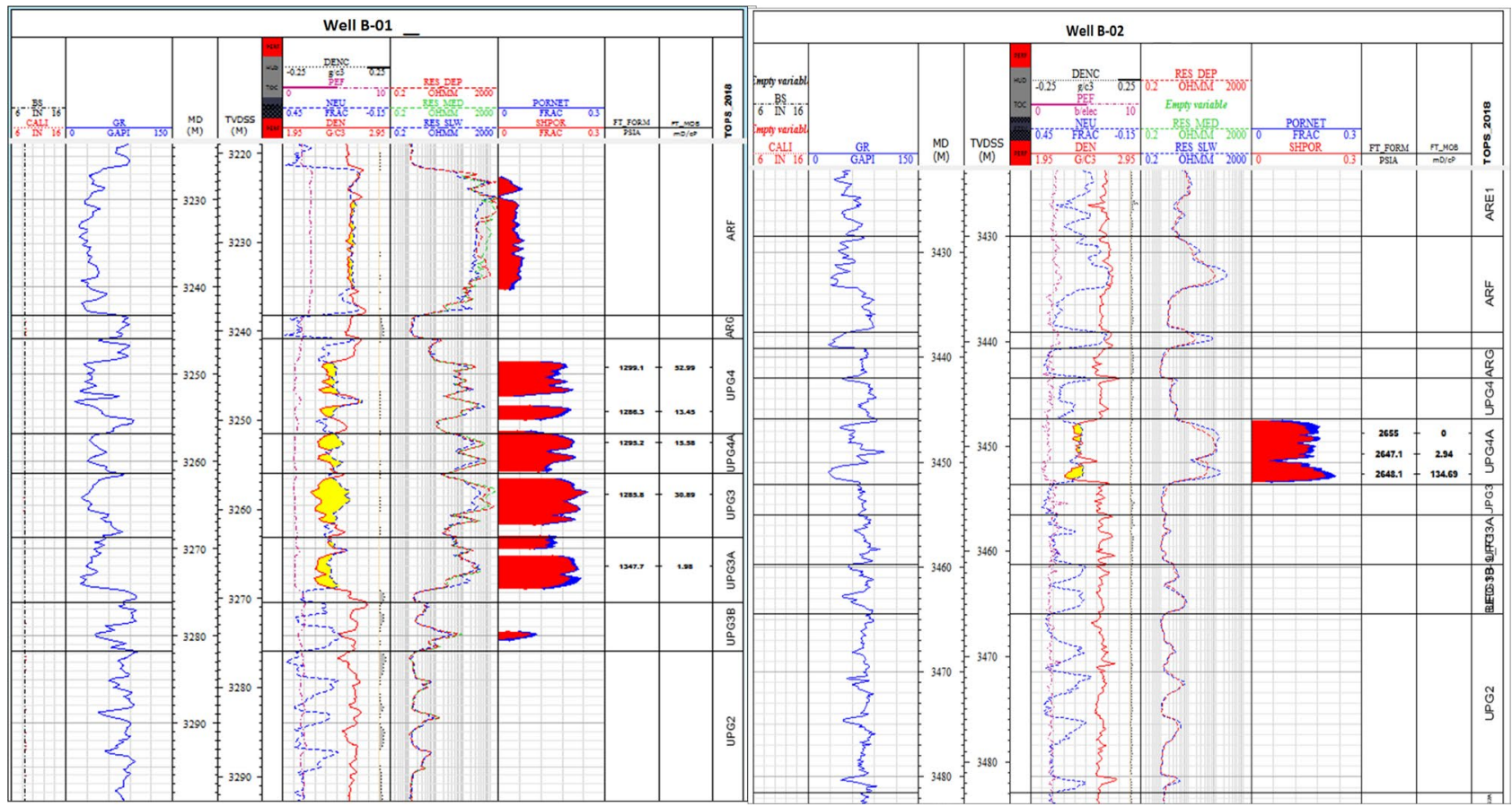

Fig. 3 The well logs for Well B-01 and Well B-02
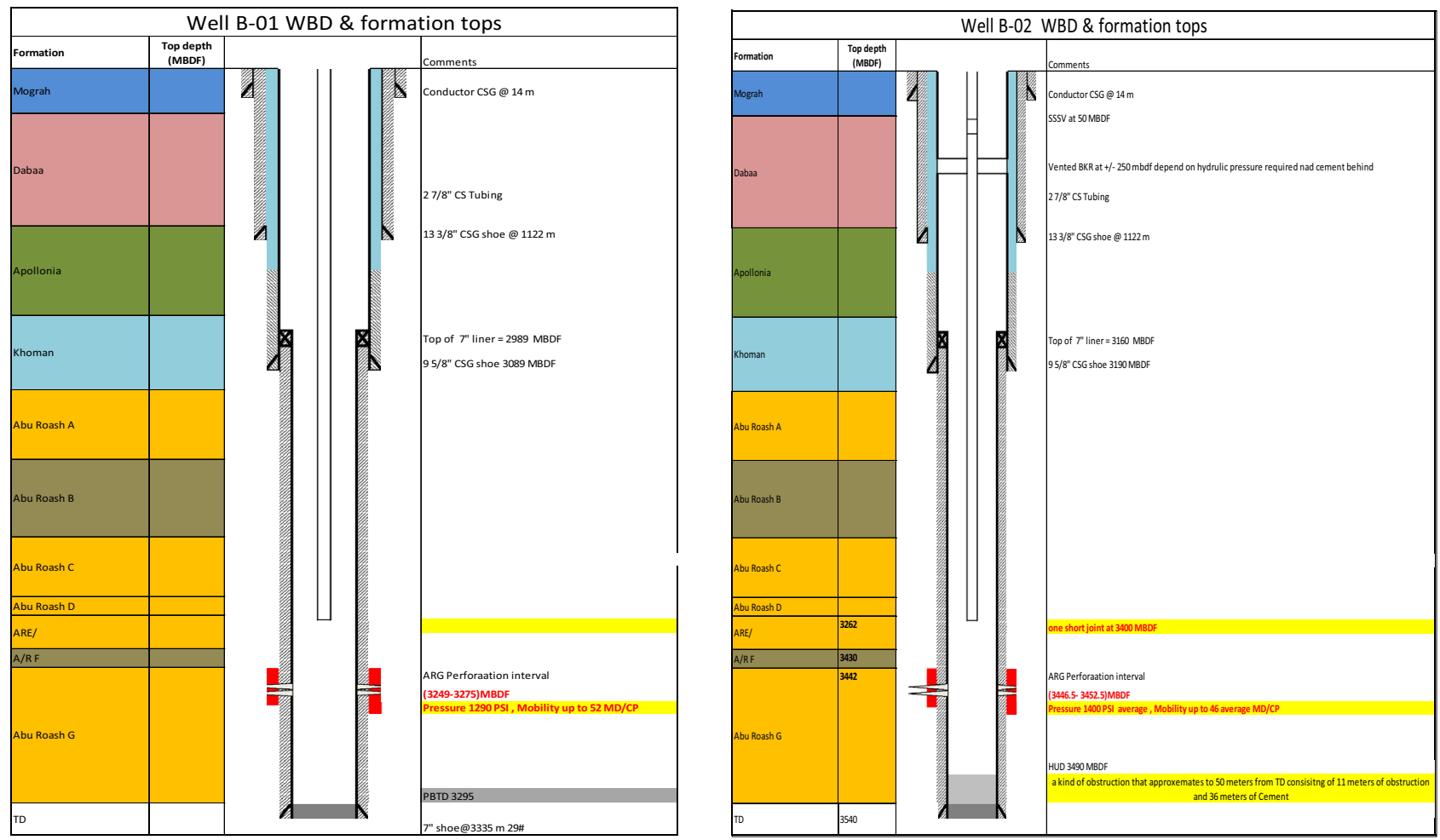

Fig. 4 Well bore diagram with formation tops for Wells B-01 and B-02 
Table 2 The fracturing data of the first conventional fluid fracture for Well B-01 and Well B-02

\begin{tabular}{lll}
\hline Well & Well B-01 & Well B-02 \\
\hline Parameter & & \\
Formation/lithology & ARG/sandstone & ARG/sandstone \\
Pumping rate, BPM & 20 & 18 \\
Gel loading, ppg & 40 & $35 \& 30$ \\
Fluid type & Conventional & Conventional \\
& cross-linked & cross-linked \\
& gel & gel \\
Job liquid volume, bbl & 760 & 1450 \\
Proppant mass, Ibs & 49,584 & 82,871 \\
Max. proppant concentration, ppg & 7 & 7 \\
$X_{f}$, m & 48 & 110.2 \\
$W_{f}$, in & 0.32 & 0.35 \\
$H_{f}$, m & 30 & 33.5 \\
FC, md.ft & 52,410 & 22,681 \\
Average gel fluid retained factor & 0.6 & 0.3 \\
\hline
\end{tabular}

2. NEF fracturing succeeds to recover oil from previously fractured wells using conventional fracturing fluids. In addition, a comparison between the results of NEF fractured and conventional fluid fractured wells is presented, through testing and live production.

3. Adding a component such as methanol to an energized system would help in fracturing tight gas reservoirs where aqueous phase trapping is a potential problem.

4. NEF treatments are more economically preferable than conventional treatments in terms of overall cost.

\section{Field applications}

In Egypt, where $\mathrm{CO}_{2}$ is not used due to the mentioned reasons in the previous section, only $\mathrm{N}_{2}$ is used in energizing the liquid phase to fracture depleted and low-pressure reservoirs with foam qualities ranging from 20 to $50 \%$. Foam quality is limited to this range because the follows:
Table 3 The re-fracturing data for Well B-01 and Well B-02

\begin{tabular}{lll}
\hline Well & Well B-01 & Well B-02 \\
\hline Parameter & & \\
Fracturing type & Channel fracturing & Channel fracturing \\
Pumping rate & 20 & 18 \\
Gel loading, ppg & $35 \& 30$ & $35 \& 30$ \\
Fluid type & NE cross-linked gel & NE cross-linked gel \\
N2 Foam quality \% & $35 \%$ & $30 \%$ \\
Proppant mass, Ibs & 76,040 & 89,290 \\
Max. pressure, psi & 5505 & 8890 \\
$X_{f}$, m & 87.5 & 190 \\
$W_{f}$, in & 0.28 & 0.39 \\
$H_{f}, \mathrm{~m}$ & 29.8 & 15 \\
FC, md.ft & 53,720 & 59,817 \\
Average gel fluid & 0.8 & 0.6 \\
retained factor & & \\
\hline
\end{tabular}

1. Previous studies showed that under a wide range of reservoir conditions, foam qualities of 20 to $50 \%$ are optimum because they allow enough gas to saturate the liquid, to maximize gas flow back, and they yield long fractures. Higher quality (up to 70\%) may be necessary if shorter and wider fractures are required (Kyle et al. 2009).

2. Increasing foam quality will require larger supply of gas, special surface and subsurface equipment.

\section{Effect of using NEF fracturing in Egyptian Western Desert}

This section reflects successful applications of using 20-50\% quality NEF in the Egyptian Western Desert. NEF showed very good and satisfactory results when used in stimulating low-pressure reservoirs as well as high-pressure ones. The following section shows the rise of using NEF in fracturing low-pressure reservoirs in the Egyptian Western Desert. It was started by 2 wells that were fractured using conventional
Table 4 Comparison between conventional fluid and NEF fracturing for Well B-01 and Well B-02

\begin{tabular}{|c|c|c|c|c|c|c|c|c|}
\hline \multirow[t]{2}{*}{ Parameter } & \multicolumn{4}{|c|}{ WELL B-01 } & \multicolumn{4}{|c|}{ WELL B-02 } \\
\hline & \multicolumn{2}{|c|}{$\begin{array}{l}\text { After conven- } \\
\text { tional fluid } \\
\text { fracturing }\end{array}$} & \multicolumn{2}{|c|}{$\begin{array}{l}\text { After NEF } \\
\text { fracturing }\end{array}$} & \multicolumn{2}{|c|}{$\begin{array}{l}\text { After conven- } \\
\text { tional fluid } \\
\text { fracturing }\end{array}$} & \multicolumn{2}{|c|}{$\begin{array}{l}\text { After NEF } \\
\text { fracturing }\end{array}$} \\
\hline Gross rate, $\mathrm{BPD}$ & 125 & & 720 & & 220 & & 520 & \\
\hline FOI, & 5.76 & & & & 2.36 & & & \\
\hline Job liquid volume, bbl & 760 & & 881 & & 1450 & & 1518 & \\
\hline \multirow[t]{3}{*}{ Fracture dimensions } & $X_{f}$ & $48 \mathrm{~m}$ & $X_{f}$ & $87 \mathrm{~m}$ & $X_{f}$ & $110 \mathrm{~m}$ & $X_{f}$ & $190 \mathrm{~m}$ \\
\hline & $H_{f}$ & $30 \mathrm{~m}$ & $H_{f}$ & $30 \mathrm{~m}$ & $H_{f}$ & $33 \mathrm{~m}$ & $H_{f}$ & $15 \mathrm{~m}$ \\
\hline & $W_{f}$ & 0.32 in & $W_{f}$ & 0.28 in & $W_{f}$ & 0.35 in & $W_{f}$ & 0.3 in \\
\hline FC, md.ft & 32,410 & & 53,720 & & 22,681 & & 59,817 & \\
\hline Average gel fluid retained factor & 0.6 & & 0.8 & & 0.3 & & 0.6 & \\
\hline
\end{tabular}


Table 5 Pre- and post-NEF fracturing results for successful applications in the Egyptian Western Desert

\begin{tabular}{|c|c|c|c|c|c|c|c|c|c|c|c|}
\hline Parameter & Well type & Formation & BHP, psi & BHT, F & $\mathrm{K}$, md & $Q_{o}, \mathrm{BPD}$ & W. C. ${ }_{0}, \%$ & $\begin{array}{l}\text { N2 quality } \\
\text { used, \% }\end{array}$ & $Q_{f}, \mathrm{BPD}$ & W. C.,$\%$ & FOI \\
\hline \multicolumn{12}{|l|}{ Well } \\
\hline Well A-01 & Oil & ARG & 4500 & 250 & 13 & 870 & $5 \%$ & $35 \%$ & 1800 & $2 \%$ & 2.07 \\
\hline Well S-01 & Oil & ARG & 2500 & 230 & 38 & 230 & $55 \%$ & $40 \%$ & 400 & $3 \%$ & 1.74 \\
\hline Well S-02 & Oil & ARE & 3400 & 246 & 27 & 210 & $38 \%$ & $35 \%$ & 450 & $24 \%$ & 1.36 \\
\hline Well S-03 & Oil & ARG & 3600 & 240 & 29 & 265 & $47 \%$ & $40 \%$ & 525 & $34 \%$ & 1.98 \\
\hline Well SC-01 & Oil & ARG & 4235 & 240 & 28 & 543 & $0 \%$ & $30 \%$ & 2670 & $9 \%$ & 4.9 \\
\hline Well SC-02 & Oil & U.BAH & 4200 & 230 & 9 & 180 & $61 \%$ & $25 \%$ & 680 & $67 \%$ & 3.78 \\
\hline Well SC-03 & Oil & ARG & 4300 & 240 & 37 & 370 & $10 \%$ & $35 \%$ & 1016 & $0 \%$ & 2.75 \\
\hline Well YC-01 & Oil & ARG & 3800 & 236 & 48 & 220 & $45 \%$ & $40 \%$ & 770 & $2 \%$ & 3.5 \\
\hline Well YC-09 & Oil & ARG & 2300 & 238 & 22 & 450 & $60 \%$ & $35 \%$ & 1650 & $75 \%$ & 3.67 \\
\hline Well Y-10 & Oil & ARG & 5000 & 240 & 19 & 90 & $35 \%$ & $30 \%$ & 480 & $20 \%$ & 5.33 \\
\hline Well BS-01 & Oil & BAH & 3308 & 244 & 5.8 & 130 & $0 \%$ & $40 \%$ & 850 & $20 \%$ & 6.53 \\
\hline Well BC-01 & Oil & ARG & 4400 & 235 & 31 & 110 & $12 \%$ & $25 \%$ & 370 & $2 \%$ & 3.36 \\
\hline Well YC-4 & Oil & ARG & 3000 & 240 & 18 & 150 & $15 \%$ & $35 \%$ & 290 & $20 \%$ & 1.93 \\
\hline Well YC-6 & Oil & ARG & 1780 & 240 & 32 & 310 & $33 \%$ & $30 \%$ & 550 & $10 \%$ & 1.77 \\
\hline Well YC-7 & Oil & ARG & 1700 & 240 & 27 & 170 & $15 \%$ & $30 \%$ & 330 & $5 \%$ & 1.94 \\
\hline Well S-04 & Oil & U.BAH & 3500 & 253 & 33 & 335 & $24 \%$ & $35 \%$ & 735 & $35 \%$ & 2.19 \\
\hline Well S-05 & Oil & ARG & 3400 & 230 & 38 & 160 & $25 \%$ & $40 \%$ & 400 & $35 \%$ & 2.5 \\
\hline Well S-06 & Oil & ARG & 5500 & 220 & 32 & 220 & $17 \%$ & $40 \%$ & 490 & $5 \%$ & 2.23 \\
\hline Well N-05 & Oil & BAH & 2800 & 235 & 28 & 310 & $16 \%$ & $40 \%$ & 480 & $15 \%$ & 1.54 \\
\hline Well Q-01 & Oil & BAH & 1700 & 180 & 24 & 470 & $32 \%$ & $30 \%$ & 840 & $35 \%$ & 1.78 \\
\hline Well Q-03 & Oil & BAH & 1650 & 175 & 26 & 356 & $37 \%$ & $30 \%$ & 790 & $49 \%$ & 2.2 \\
\hline Well Q-08 & Oil & BAH & 1850 & 182 & 23 & 490 & $29 \%$ & $32 \%$ & 900 & $41 \%$ & 1.83 \\
\hline Well F-04 & Oil & M.BAH & 1700 & 177 & 28 & 230 & $50 \%$ & $25 \%$ & 550 & $55 \%$ & 2.39 \\
\hline Well F-05 & Oil & M.BAH & 1680 & 181 & 32 & 287 & $53 \%$ & $27 \%$ & 600 & $65 \%$ & 2.1 \\
\hline Well F-08 & Oil & M.BAH & 1750 & 190 & 25 & 265 & $64 \%$ & $26 \%$ & 490 & $60 \%$ & 1.85 \\
\hline Well B-09 & Oil & A5 & 1800 & 147 & 19 & 280 & $14 \%$ & $45 \%$ & 535 & $16 \%$ & 1.9 \\
\hline Well NP-01 & Oil & U.BAH & 1890 & 190 & 39 & 147 & $35 \%$ & $30 \%$ & 390 & $55 \%$ & 2.65 \\
\hline Well NP-03 & Oil & U.BAH & 2156 & 185 & 34 & 220 & $45 \%$ & $37 \%$ & 410 & $61 \%$ & 1.83 \\
\hline Well NP-09 & Oil & U.BAH & 2046 & 194 & 28 & 195 & $51 \%$ & $32 \%$ & 350 & $45 \%$ & 1.79 \\
\hline Well K-01 & Oil & A.BUEIB & 4500 & 220 & 34 & 250 & $10 \%$ & $40 \%$ & 480 & $12 \%$ & 1.92 \\
\hline Well K-03 & Oil & A.BUEIB & 3900 & 230 & 28 & 240 & $15 \%$ & $35 \%$ & 410 & $16 \%$ & 1.7 \\
\hline Well K-04 & Oil & A.BUEIB & 4200 & 235 & 41 & 290 & $3 \%$ & $30 \%$ & 500 & $14 \%$ & 1.72 \\
\hline Well K-07 & Oil & A.BUEIB & 4300 & 240 & 38 & 310 & $5 \%$ & $33 \%$ & 490 & $19 \%$ & 1.58 \\
\hline Well K-09 & Oil & A.BUEIB & 4000 & 240 & 18 & 320 & $18 \%$ & $39 \%$ & 570 & $10 \%$ & 1.78 \\
\hline Well K-11 & Oil & A.BUEIB & 4600 & 230 & 24 & 380 & $22 \%$ & $29 \%$ & 595 & $8 \%$ & 1.56 \\
\hline Well M-11 & Oil & $\mathrm{ARG}$ & 4000 & 230 & 4 & 115 & $11 \%$ & $20 \%$ & 360 & $4 \%$ & 3.13 \\
\hline Well M-13 & Oil & ARG & 2900 & 237 & 11 & 250 & $25 \%$ & $40 \%$ & 350 & $25 \%$ & 1.4 \\
\hline Well BQ-03 & Oil & ARE & 2140 & 239 & 12 & 70 & $0 \%$ & $35 \%$ & 160 & $12 \%$ & 2.28 \\
\hline Well B-16 & Oil & L-ARG & 4100 & 260 & 16 & 135 & $0 \%$ & $30 \%$ & 410 & $5 \%$ & 3 \\
\hline
\end{tabular}

fluid fracturing, but showed very disappointing results in both production and sustainability. They were then stimulated using NEF fracturing. Their impressive results made NEF fracturing the ideal choice to stimulate depleted and low-pressure reservoirs.
Wells (B-01 and B-02) were drilled in the same block (B) targeting the same reservoir ARG. Figure 2 illustrates the topographic map for the well in block (B).

Well B-01 successfully encountered the primary targeted sand on upper-ARG level of about $22.6 \mathrm{~m}$ net sand with good quality (average porosity $=0.19 \%$ ) and reservoir 


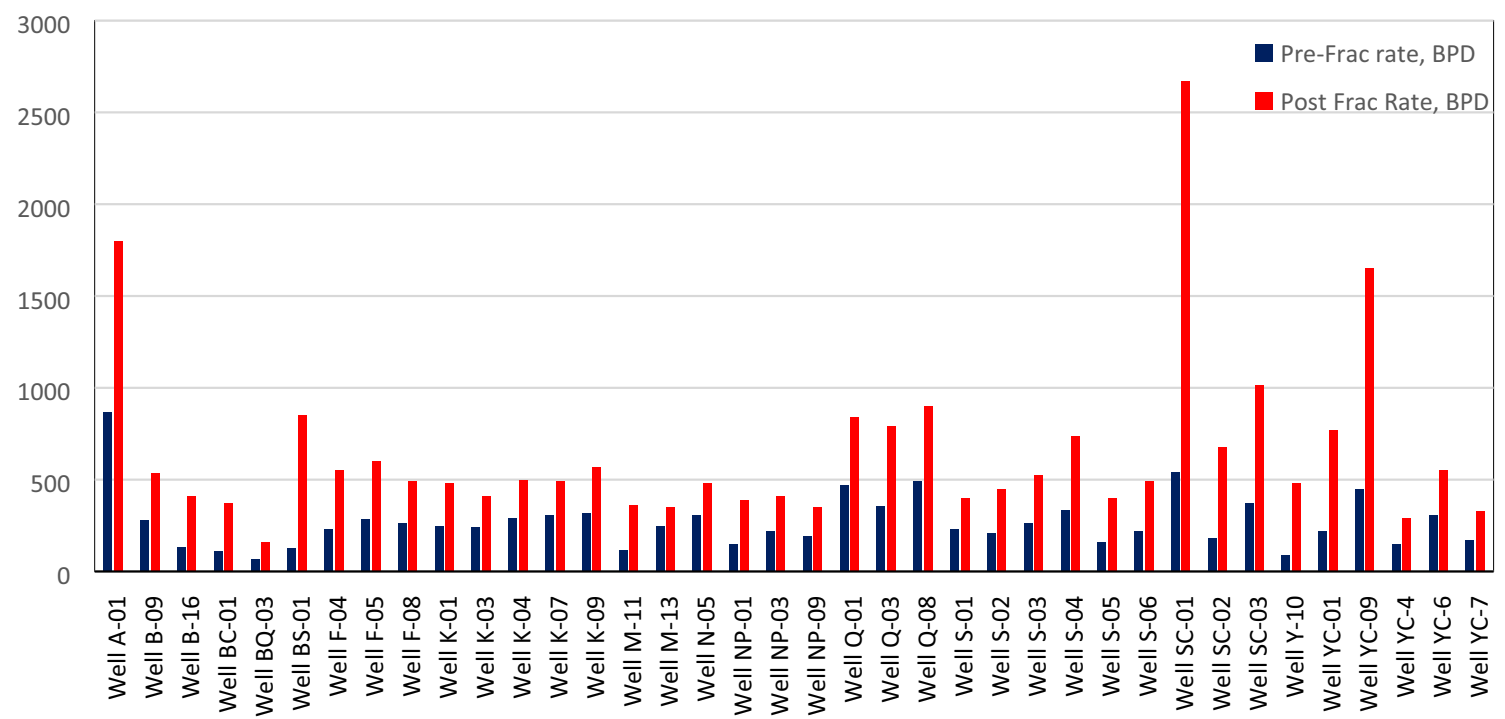

Fig. 5 Summary of pre- and post-fracturing gross rates for a sample of successful applications in the Egyptian Western Desert

pressure found around 1400 psi. Well B-02 successfully encountered the primary targeted sand on upper-ARG level of about $6 \mathrm{~m}$ net sand, with good quality (average porosity $=0.16 \%)$ and reservoir pressure found around 1400 psi. At first, the two wells were stimulated using conventional fracturing fluid, and Figs. 3 and 4 show the well logs and the completion summary for the two wells, respectively. Table 2 illustrates the data for the first conventional fluid fracturing for both wells. It indicates very low average gel fluid retained factor, which indeed affects the fracture conductivity, as it will appear in the production data of the two wells.

\section{Results and discussion}

Both Well B-01 and Well B-02 were tested after their first conventional fluid channel fracturing. Their production data showed very low and declining rate with time, and the production data for Well B-01 after the first conventional fluid fracturing while lifting with $\mathrm{N}_{2}$ showed oil rate of 7-70 BOPD. While the production data for Well B-02 showed oil rate of 50-600 BOPD. The production rates of both wells were very low and declined rapidly. After these disappointing results of the conventional fluid fracturing, both wells were re-fractured using NEF and showed exceptional results. The challenge was to bypass the damage caused by the first conventional fracturing fluids and achieve good and sustainable production rates despite their low reservoir pressures. Table 3 demonstrates the re-fracturing data for both wells.

The production figure of Well B-01 after NEF re-fracturing showed a gross rate of $\mathbf{7 2 0} \mathrm{BPD}$, which sustained for nearly one year, while the production figure of Well B-02 after NEF re-fracturing showed a gross rate of $\mathbf{5 2 0}$ BPD, which sustained for 9 months.

As demonstrated in Table 4, NEF fracturing showed very good and sustainable production results compared to those of conventional fluid fracturing as follows:

1. Both wells showed very good and sustainable rates after NEF fracturing compared to their results after conventional fluid fracturing.

2. The fracture half-lengths $X_{f}$ for Well B-01 and Well B-02 obtained from NEF fracturing are $87 \mathrm{~m}$ and $190 \mathrm{~m}$, respectively, which are nearly double the half-lengths obtained from conventional fluid fracturing using the same liquid volumes.

3. The fracture conductivities for Well B-01 and Well B-02 obtained from NEF fracturing are 53,720 md.ft and 59,817 md.ft, which are nearly double that obtained from the conventional fluid fracturing.

4. The average gel retained factor is higher in case of NEF fracturing for both wells ( 0.8 and 0.6 ), respectively, than in case of conventional fluid fracturing (0.6 and 0.3), which is the percent of gel fluid extracted after treatment. The higher this percent, the lower the residual gel material left in the formation, which affects the fracture conductivity.

\section{Successful applications of NEF fracturing in the Egyptian Western Desert}

After the impressive results of NEF fracturing in Wells B-01 and B-02, it is now a role of thumb to use NEF in fracturing

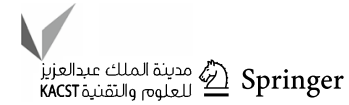




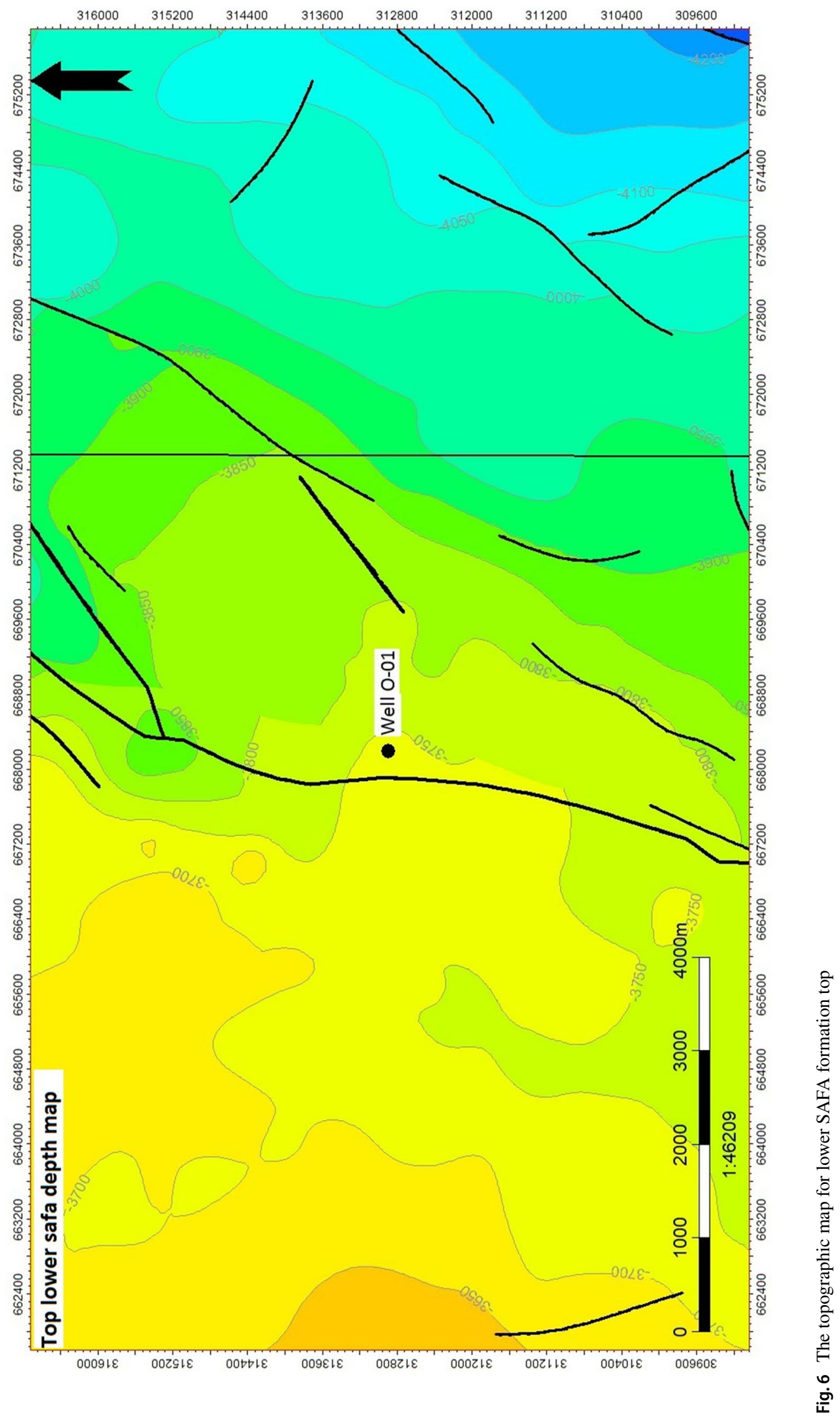




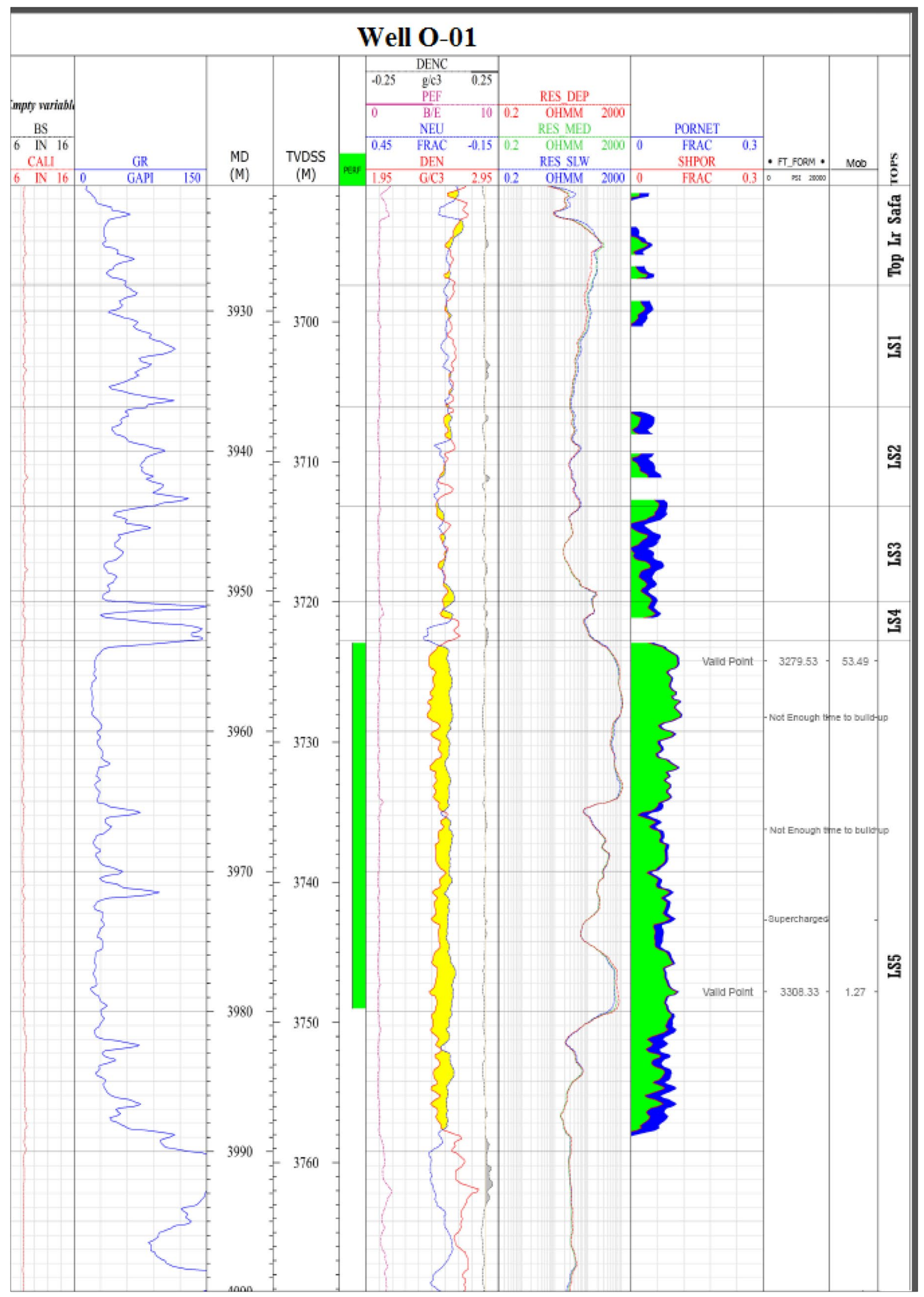

Fig. 7 Well O-01 open hole log 


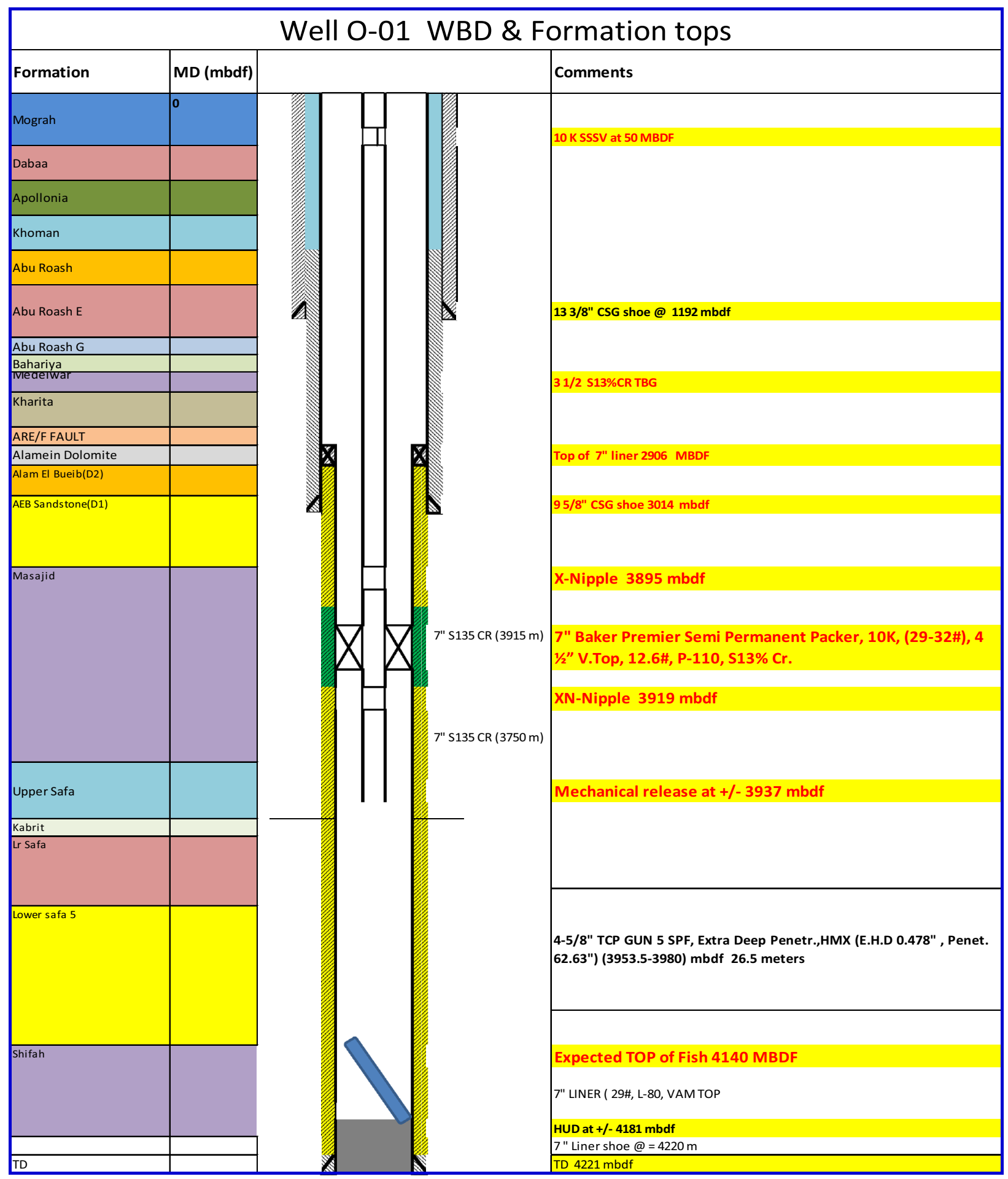

Fig. 8 Well bore diagram and formation tops for Well O-01

low-pressure reservoirs to minimize the formation damage and aid in the flow-back operations after treatment. Table 5 shows a summary of successful applications of NEF in fracturing low-pressure reservoirs in the Egyptian Western Desert. Figure 5 summarizes pre- and post-energized fluid fracturing gross rates for a sample of wells in the Egyptian Western Desert.

Well O-01 gas producer was a special challenge. Well O-01 successfully encountered the primary targeted sand on lower SAFA level of about $26.5 \mathrm{~m}$ net sand with moderate 
Table 6 Reservoir and fracturing data for Well O-01

\begin{tabular}{ll}
\hline Parameter & Well O-01 \\
\hline Type & Gas producer \\
Formation/lithology & L-SAFA/sandstone \\
BHP, psi & 3300 \\
BHT, $f$ & 270 \\
$K$, md & 0.2 \\
$E * 10^{\wedge} 6$ & 6.2 \\
$\nu$ & 0.16 \\
Perforation interval, mbdf & $3953-3980$ \\
N2 quality used, $\%$ & $25 \%$ \\
$Q_{o}$, MMSCFD & 0.5 \\
$Q_{f}$, MMSCFD & 2.8 \\
FOI & 5.6 \\
\hline
\end{tabular}

quality (average porosity $=0.08 \%$ ), reservoir pressure found depleted around (3300 psi) and very tight (0.2 md). Figure 6 illustrates the topographic map for L-SAFA formation, and Figs. 7 and 8 show the well log and completion summary for Well 0-01, while Table 6 illustrates its reservoir and petro-physical data, which indeed requires a special type of stimulation.

The limited drawdown led to deciding that energizing fluid fracturing is the way to go, but another issue was encountered which is the APT (aqueous phase trapping) due to the very low reservoir permeability. Adding a component such as methanol to the energized fluid system could help. The final decision was made to stimulate that well using foam-methanol fracturing, where $10 \%$ methanol was added to the fracturing fluid before energizing with $25 \%$ quality $\mathrm{N}_{2}$. Well O-01 showed good enhancement in gas production rate, as shown in Fig. 9 a, quick comparison between pre- and post-fracturing gas rates, where pre-fracturing gas rate was 0.5 MMSCFD, while post-fracturing gas rate was 2.8 MMSCFD with a FOI equal to 5.6.

\section{Economic benefits of using NEF fracturing}

Granting the very impressive results of NEF in fracturing depleted and low-pressure reservoirs on production rates and sustainability. NEF fracturing treatments appear to be more economically preferable to conventional fluid fracturing ones.

In this section, we will take a sample of wells to discuss the economic benefits of using NEF fracturing over conventional fluid fracturing in depleted and low-pressure reservoirs.
Wells A-01, A-02 and A-03 were drilled in the same reservoir block, targeting ARG formation. Figures 10 and 11 show the topographic map and the well logs for the three wells, respectively, while Fig. 12 shows the well completion summary for the three wells. Wells A-02 and Well A-03 were stimulated using conventional fluid fracturing, while Well A-01 was stimulated using 35\% NEF fracturing. As shown in Table 7, it is obvious that treatments of the three wells used nearly the same liquid volumes and proppant mass. The treatment cost of NEF fracturing is about 15-20\% much more than that of conventional fluid treatments. However, this additional cost is offset by the cost of unloading and flowing back the well in case of conventional treatments. Also NEF treatments showed very impressive estimated ultimate recovery (EUR), these reasons make NEF treatments more economically preferable than conventional ones.

Figure 13 shows the cumulative production from the three wells during a three-month period, represented as a fraction of original oil in place $(\mathrm{N})$. Well A-01 produced about $0.016 \mathrm{~N}$ gross production, while Wells A-02 and A-03 produced about $0.009 \mathrm{~N}$ and $0.0092 \mathrm{~N}$.

\section{Conclusions and recommendations}

Based on the field data conducted and presented in this paper, the following conclusions can be drawn:

1. 20 to $50 \%$ quality NEF fracturing showed exceptional results mainly in low-pressure reservoirs in the Egyptian Western Desert, in addition to their good results in highpressure reservoirs.

2. Adding a component such as methanol to an energized system helps in fracturing tight gas reservoirs where

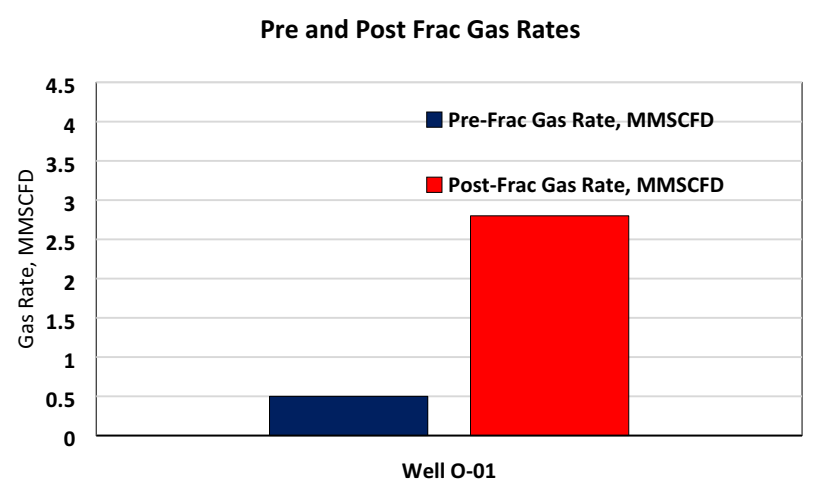

Fig. 9 Pre- and post-NEF fracturing rates for Well O-01 


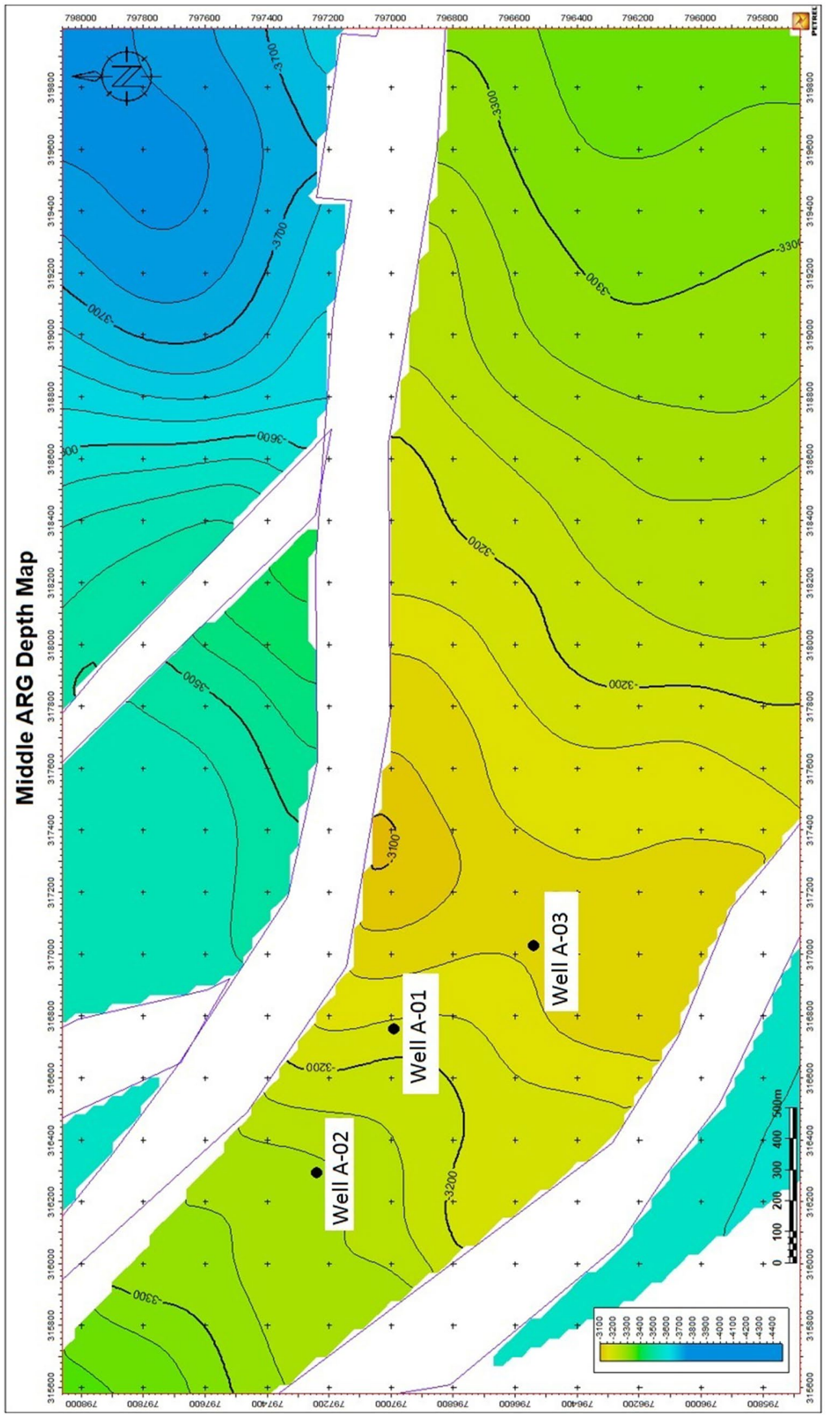

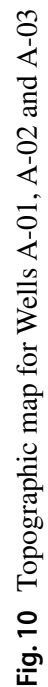




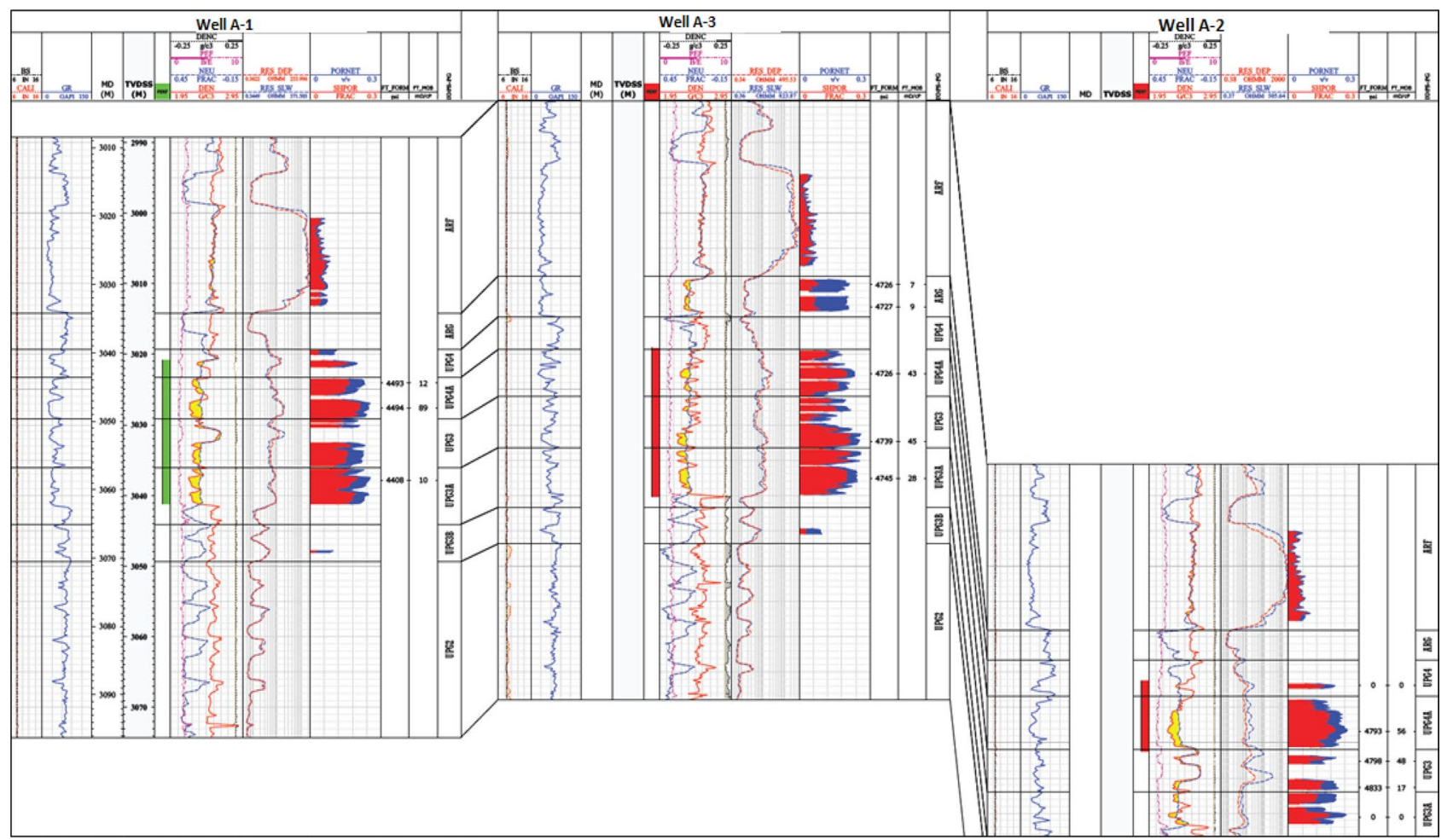

Fig. 11 Well $\operatorname{logs}$ for the 3 offset wells: Well A-1, Well A-2 and Well A-3

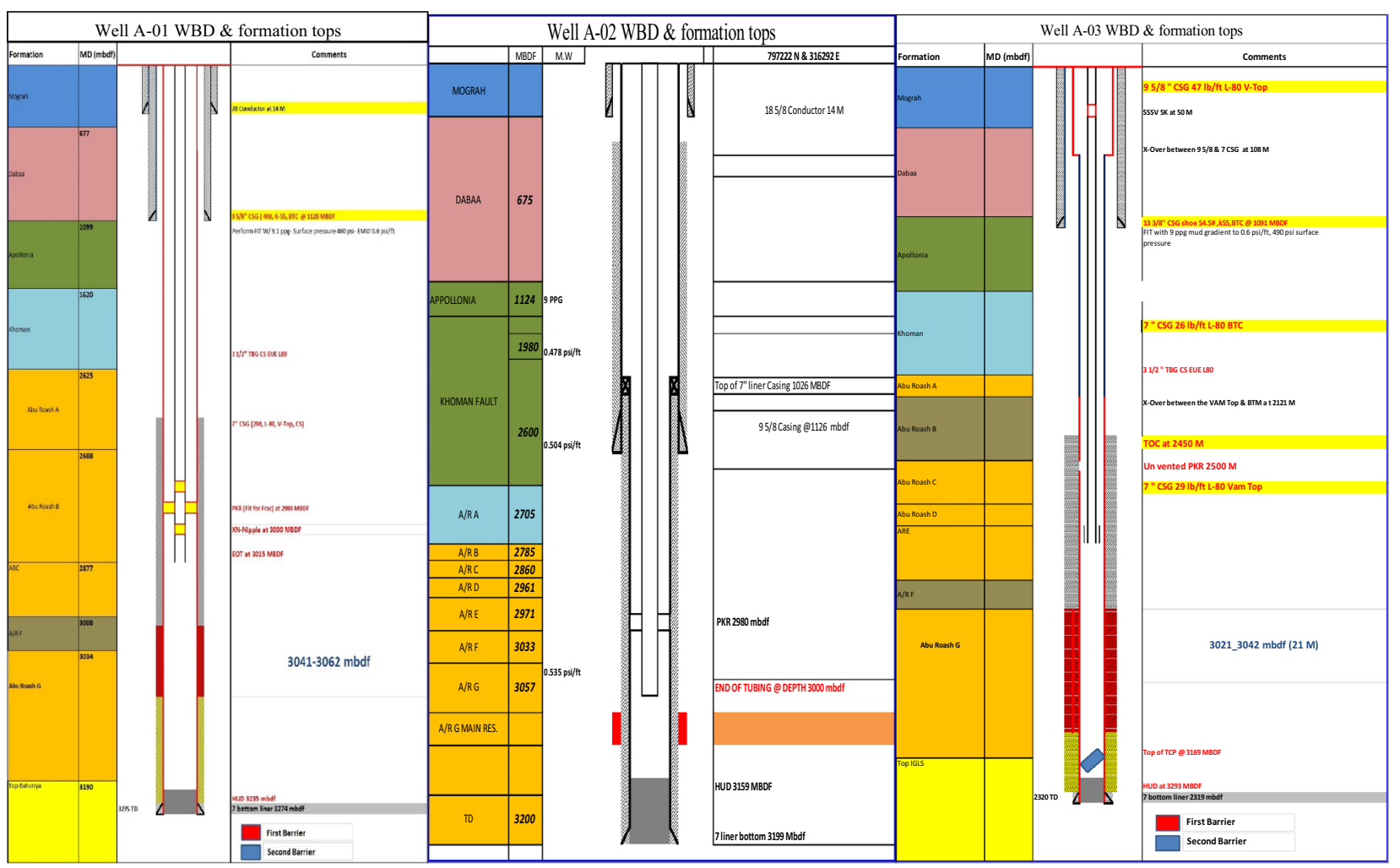

Fig. 12 Well bore diagram for the three Wells A-01, A-02 and A-03 
Table 7 Fracturing and economic data for Wells A-01, A-02 and A-03
Fig. 13 Cumulative production of the three Wells A-01, A- 02 and A- 03 for a period of 3 months

\begin{tabular}{llll}
\hline Parameter & Well A-01 & Well A-02 & Well A-03 \\
\hline Type & Oil producer & Oil producer & Oil producer \\
Formation/lithology & ARG/sandstone & ARG/sandstone & ARG/sandstone \\
BHP, psi & 4500 & 4700 & 4700 \\
BHT, $f$ & 250 & 250 & 250 \\
$K$, md & 27 & 30 & 39 \\
$E^{*} 10^{\wedge} 6$ & 3 & 2.7 & 3 \\
$\nu$ & 0.218 & 0.26 & 0.213 \\
Perforation interval, mbdf & $3041-3062$ & $3070-3085$ & $3031-3042$ \\
Fracturing fluid type & $35 \%$ NEF fracturing & Conventional fluid & Conventional \\
& & fracturing & fluid fractur- \\
& & & ing \\
Liquid volume, bbl & 1355 & 1480 & 1292 \\
Proppant mass, Ibs & 85,800 & 94,400 & 83,900 \\
Treatment cost, $1000 \$$ & 260 & 215 & 225 \\
Unloading cost, $1000 \$$ & Nil & 35 & 20 \\
Total cost, 1000 $\$$ & 260 & 250 & 245 \\
Total recovery in 3 months, $\%$ & $0.016 \mathrm{~N}$ & $0.009 \mathrm{~N}$ & $0.0092 \mathrm{~N}$ \\
\hline
\end{tabular}

aqueous phase trapping is a potential problem as the case in Well O-01.

3. NEF treatments are economically preferable than conventional fluid treatments.

Funding The author(s) received no specific funding for this work.

\section{Compliance with ethical standards}

Conflict of interest Each author has substantially contributed to conducting the underlying research and drafting this manuscript. Additionally, the named authors have no conflict of interest.

\section{CUMULATIVE PRODUCTION}

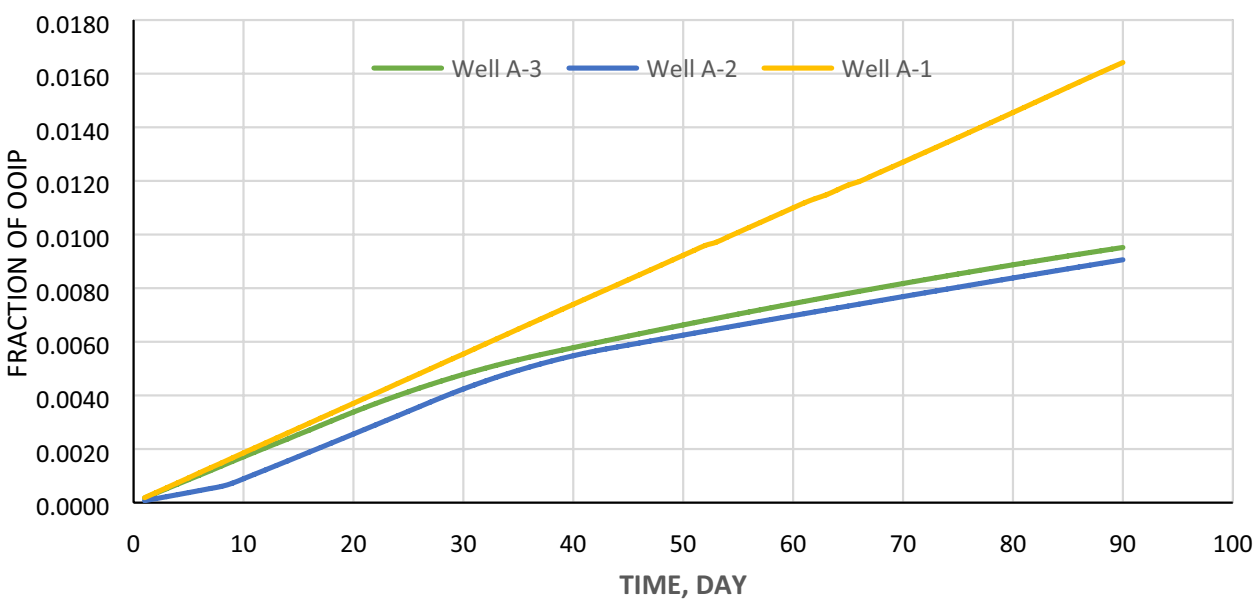

Ethical approval All of the authors have approved the contents of this paper and have agreed to the journal of petroleum exploration and production technology submission policies.

Human and animal rights The research does not involve human participants and/or animals.

Open Access This article is licensed under a Creative Commons Attribution 4.0 International License, which permits use, sharing, adaptation, distribution and reproduction in any medium or format, as long as you give appropriate credit to the original author(s) and the source, provide a link to the Creative Commons licence, and indicate if changes were made. The images or other third party material in this article are included in the article's Creative Commons licence, unless indicated otherwise in a credit line to the material. If material is not included in the article's Creative Commons licence and your intended use is not permitted by statutory regulation or exceeds the permitted 
use, you will need to obtain permission directly from the copyright holder. To view a copy of this licence, visit http://creativecommons .org/licenses/by/4.0/.

\section{References}

Bec G and Verma S (2016) Development and Field Testing Novel Natural Gas (NG) Surface Process Equipment for Replacement of Water as Primary Hydraulic Fracturing Fluid . In: Carbon Storage and Oil and Natural Gas technologies. Pittsburgh, Pennsylvania, USA

Beck G, et al. (2017) Development and Evaluation of a Mobile Plant to prepare Natural Gas for Use in Foam Fracturing Treatments. In: ASME Turbo Expo. Charlotte, North Caroline, USA: ASME, https://doi.org/10.1115/gt2017-64689

Bullen RS and Lillies AT (1983) Carbon Dioxide Fracturing Process and Apparatus.

David A, Marsden SS (1969) Fall Meeting of the Society of Petroleum Engineers of AIME. Soc Pet Eng. https://doi. org/10.2118/2544-MS

Economides MJ, Nolte KG (2000) Reservoir stimulation. Wiley, New York

Gandossi. (2013). An Overview of Hydraulic Fracturing and Other Formation Stimulation Technologies for Shale Gas Production. In: Joint Research Center of the European Commission Technical Report.

Haugen A et al (2014) Miscible and immiscible foam injection for mobility control and EOR in fractured oil-wet carbonate rocks. Transp Porous Media 104(1):109-131
Kyle EF et al. (2009) Fluid Selection for Energized Hydraulic Fractures. In: SPE Annual Technical Conference and Exhibition. Louisiana, USA. SPE 124361.

McAndrew J (2014) Extending the Application of Foam Hydraulic Fracturing Fluids. In: Unconventional resources technology conference (URTEC). https://doi.org/10.15530/URTEC-2014-19265 61

Mitchell BJ (1969) Viscosity of Foam. University of Oklahoma, Norman

Montgomery (2013) Fracturing fluid components, effective and sustainable hydraulic fracturing. In: Rob J (ed) InTech. http://www. intechopen.com/books/effective-and-sustainable-hydraulic-fract uring/fracturing-fluid-components. Accessed 22 May 2020

Petty CB, Hendrickson AR, Brown LS (1964) Liquid Nitrogen in Well Operations. USA Patent No. 3358763.

Steven RG et al (1983) Foam stimulation. J Petrol Technol 35:597-602

Verma $S$ et al. (2016) Novel Fracturing Process Utilizing Natural Gas. In: AICHE Annual Meeting. San Francisco, California, USA: AICHE

Watkins EK, et al. (1983) A New Cross-linked Foamed Fracturing Fluid. Division of Dow Chemicals SPE 12027.

$\mathrm{Yu}$ W et al (2015) Numerical study of the effect of uneven proppant distribution between multiple fractures on shale gas well performance. Fuel 142:189-198

Publisher's Note Springer Nature remains neutral with regard to jurisdictional claims in published maps and institutional affiliations. 